\title{
Parental expectations of and satisfaction with the services of preschool centres
}

\section{A case study in Songkhla Province, Thailand}

\author{
Wanna Prayukvong
}

Mahidol University, Nakhonsawan Campus, Nakhon Sawan, Thailand

Amporn Sornprasith

Prince of Songkhla University, Songkhla Province, Thailand, and

Morris John Foster

Kingston Business School, Kingston University, Kingston-Upon-Thames, UK

Services of

\begin{abstract}
Purpose - This paper aims to study parental expectations of and satisfaction with overall services of preschool centres and to determine the factors which affect parents' satisfaction in a part of one of Thailand's southern provinces.

Design/methodology/approach - Data were collected using a structured questionnaire from parents of children attending 29 day-care or preschool centres in Songkhla Province, South Thailand, over a two-month period in the Spring 2014. The data were analysed mainly using descriptive statistics and some correlation analyses with subsequent logical interpretation.
\end{abstract}

Findings - Given the location and non-compulsory nature of the childcare provision being assessed, it would seem fair to say that the answer to the overarching objective was fairly positive. Expectations were non-trivial; parents looked for more than "baby-minding" and expected there to be some appropriately qualified staff. The perceived satisfaction levels indicate that there is nevertheless scope for improvement.

Research limitations/implications - The sample studied is from a limited geographical region of Thailand; hence, there must be some caution in making recommendations for the whole country.

Practical implications - As the outcomes being delivered are seen to be mainly positive by parents and guardians, the policy implication for the Thai Government is that they should continue to promote, and ideally enhance, this kind of early years provision. Results suggest that Thai parents would be well advised to make use of childcare centres to promote the socialisation and development of their children.

Originality/value - The originality of the work derives from the lack of similar systematic studies in Thailand and, in particular, for the rural southern provinces.

Keywords Expectations, Thailand, Childcare centre, Parents' satisfaction, Preschool, Songkhla

Paper type Research paper

This manuscript is a part of the research and development project entitled "Preschool Centres Development in Songkhla: A Case Study of Local Curriculum and Integrated Lesson Plans for Early Childhood Development in the Pilot Preschool Centres" and is funded by Prince of Songkhla University (PSU) through the contract No. ART560107S. The authors would like to thank Robin Waterston for providing useful comments about our text; Miss Raksita Subaramdecha, an assistant researcher of this project; staff of the ACC, PSU; and staff of all childcare centres studied in this research.

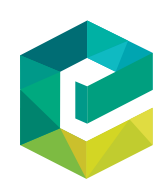


JME

12,3

250

\section{Introduction}

The significance of preschool education has been emphasised in Thailand since the National Education Act B.E. 2542 (1999) was launched on 20 August 1999 (ONEC, 1999). Besides the Ministry of Education, the Ministry of Health and the Ministry of Social Development and Human Security have also provided several strategic plans and programmes about early childhood development. The local administrative organisation is responsible for providing preschool education according to the National Education Act B.E. 2542 (1999). All childcare centres established by organisations such as the Department of Community Development; the Ministry of Interior; Department of Religious Affairs, the Ministry of Culture; and the Office of Primary Education, the Ministry of Education were transferred to the local administrative organisation in 2002. In all, since that transfer, 19,157 childcare centres across the country have been under the jurisdiction of the local administrative organisation [Department of Local Administration Organization (DLAO), 2014].

Both direct and indirect budgets from both central and local government were continuously provided to support and develop childcare centres, especially educating and training all caregivers in each childcare centre to have a formal qualification. A National Curriculum for preschool education, together with a plan of learning activities preparation, was developed as a guideline for caregivers to educate children in childcare centres to achieve an ultimate goal of the whole development of a child in physical, mental, emotional, social and intellectual domains, promoting morality and ethics and encouraging children to do their daily activities on their own [Ministry of Education (MOE), 2013; DLAO, 2014].

Although preschool education is not compulsory in Thailand, some local administrative organisations set up a policy to encourage parents to enrol their preschool-age children as a key performance index. In 2013, the Office of Regional Educational Sector Twelve reported that 72.5 per cent of children between three and five years of age were enrolled in a childcare centre or a kindergarten in Songkhla Province, which is located in the lower southern part of Thailand. However, parents, as their child's first teachers, still have a crucial role in their child's development in childcare centres (ONEC, 2007). Research has clearly shown that strong parent-teacher relationships lead to increased parental involvement, which has been shown to have a significant and lasting impact on children's academic achievement (Knopf and Swick, 2007, p. 291). However, more specific guidance on developing positive relationships and ideas for involving parents in the childcare centres, especially in respect of parents' expectations and satisfaction for asking their cooperation in childcare and child development, is needed for early childhood educators.

The overall objective of the research project reported here was to study parental expectations of and satisfaction with overall services of preschool centres and to determine factors which affect parents' satisfaction with the preschool education provided in a part of one of Thailand's southern provinces.

The population for the empirical work reported here were families with at least one child in pres-school education (see the Methodology section for more details). Thus, the objective noted was pursued amongst those who were actually engaged with the preschool education system. A major complementary issue, which we do not attempt to address in our primary work, is that of the degree of inclusion or exclusion of families and their children in preschool and later school education. We briefly review some of the associated issues at the end of the Literature Review section and pick up the theme again in the final section on the implications of our work. 


\section{Brief literature review}

As stated in the Introduction, prior research from beyond Thailand asserts the importance of strong parent-teacher relationships if the kind of early years education now being promoted by the Thailand's Ministry of Education is to bear fruit [e.g. Knopf and Swick (2007)]. An early study that focussed on the Thai parental attitudes was conducted by Dunn and Dasananda (1995). They noted that by 1995, at least one-third of the Thai children of three-six years of age were attending kindergarten programmes. The parent subjects in their study were reported to place a high value on the teaching of academic skills and rather less value on care giving. Since then, there have been several studies, master's theses mostly, about parents' satisfaction with childcare services in the area of each local administration organisation in Thailand (Tongsow and Runegsuwan, 2013; Marasi and Sewdon, 2013), but there remains much to be explored. Some of these Thai studies showed that factors affecting their levels of satisfaction were related to their own education. Information about parents' satisfaction, along with knowledge of the dimensions with which parents are most and least satisfied and their expectations, could be used to show whether the childcare service in a centre is effective and could serve as a basis for future development of centres to serve all families in the service area of each local administration organisation. Israsena (2007) concluded within her doctoral thesis that while Thai teachers are favourably inclined to the notion of student-centred learning with early years children, they exhibit "relatively low levels of developmentally appropriate practices". In other words, the spirit is willing, but they need help to develop professionally.

Whilst knowledge of prior work in the Thai context is clearly valuable, evidence from other places should not be overlooked as simple logic suggests that the issues involved are likely to be common across national boundaries: children, their parents and teachers have at least some aims in common [e.g. Liu et al. (2001); Kellingham et al. (2006); Frey et al. (2013)]. Liu et al. focussed on parental expectations of childcare facilities in Australia, while Kellingham et al. looked at the potential link between parental satisfaction and then loyalty to providers in the early years, educational arena. Omar et al. (2009) undertook a study in Malaysia which found that service quality, as perceived by parents, of childcare centres was positively related to parental satisfaction and trust. This may be thought to be especially relevant as Thailand and Malaysia are neighbouring ASEAN countries.

Frey et al. (2013) examined the feasibility of and satisfaction with an early childhood intervention programme in the USA (namely, the preschool version of the "First Step to Success"), investigating its treatment integrity, social validity and outcome satisfaction (The focus of the programme is on proactive interventions with children who have had poor parenting, up to and including abuse, prior to their exposure to formal preschool). The researchers found that parents' perceptions of and satisfaction with the programme's goals, procedures and outcomes were extremely favourable of the first step to success of interventions aimed at improving children's social skills and decreasing problem behaviour. In a different context, Norwegian day-care legislation places the responsibility for developing positive and close relationships with parents on the care giver [Drugli and Undheim (2012)]. They investigated the perspectives of parents and care givers regarding their partnerships when young children are in Norwegian day-care facilities. They found that most parents and care givers expressed some measure of satisfaction with their daily communication but felt that the quality of communication could be improved, particularly at the end of the day. Overall, these two pieces of research emphasise the idea that early stage interventions with children as they enter a structured care and learning environment can be very positive.
Services of preschool centres 
Dalli et al. (2011) conducted a literature review for the New Zealand Government, focussing on quality of very early years education. Their conclusions included, inter alia, that: clear programme protocols are beneficial; low adult-child ratios, well-qualified staff and a well-articulated curriculum are of benefit; and, direct benefits to children include social development and positive social behaviour. At the very least, this suggests that the Thai Government's decision to make efforts in the area of early years (preschool) is well judged. Another study supporting this view is that of Powell et al. (2010). They examined public sector school pre-kindergartens in the mid-west area of the USA. Key aspects of their findings were that parental involvement with the schools and perceived teacher responsiveness were severally, positively linked with children's social skills, maths skills (parental) and early reading (teacher responsiveness), while both aspects of adult activity were negatively related to problem behaviour amongst children. The finding about behaviour seems especially important as it indicates that preschool centre attendance can help avoid the bad behaviour of spoilt, and perhaps also ignored, young children.

An Asian study supporting this line of reasoning (particularly relevant because of its social setting) is that of Aboud (2006); looking at data from rural Bangladesh, she reports as follows (p. 46):

Four hundred children between 4.5 and 6.5 years were assessed, half in preschools and half in villages where there were no preschools. After controlling [for] the differences in children's age, nutritional status, mother's education, and assets: preschool children performed better than the comparison children on measures of vocabulary, verbal reasoning, nonverbal reasoning, and school readiness. On some indicators of social development during play, preschool children performed better, though not on the cognitive aspects of play. They were less likely to be stunted but did not differ on most other health variables.

Again, while asserting the benefits of early years interventions in some form, the study by Kabitcibasi et al. (2001) in Turkey looks at the differing effects of such interventions being home-based (i.e. the input is mainly from parents) or based at preschool day-care centres. They found that both types of intervention could be effective in the short term but the homebased approach had more enduring effects. Our thought here would be that primacy of parental input and control obviously pre-supposes that the children's parents themselves have the social and educational skills necessary to create an environment which delivers benefits. Such an assumption may be somewhat "heroic" when one looks at parents who actually are poorly educated rural peasants, of whom there are many in Thailand. This argues for day-care centres and kindergartens if all children are to have a decent chance.

While there appears to be a broad consensus as to the value of preschool education, and there have been efforts to identify positive situational factors, there may be problems too. This is illustrated by a study in Hong Kong of Ho (2008). She highlights the potential tensions inherent in preschool provision where parents already worry about their children's future school attainment before they even arrive at a "proper" school. These tensions are basically between the parents' desire for academic preparation for primary school and the professionals' belief in the value to children of learning through play. This is perhaps likely to be less of an issue in rural Thailand but illustrates the principle that the actors in the play may not always begin by pulling in the same direction, albeit all of them have the children's interests at heart in a broad sense.

We pause here to consider the issue of inclusion/exclusion, as it relates to the education of young children in Southeast Asia, of which Thailand is part. There are a variety of reasons why children may not participate in preschool education: these include social convention (ideas such as "parents know best"); ability to pay, given that such education is often not funded by the state; and unwillingness of providers to deal with handicapped children 
(Bray, 1998; de Los Angeles-Bantista, 2004; Rao and Pearson, 2009; Kim and Umayahara, 2010; Gangopadhyay and Bhattacharyay, 2015).

Kim and Umayahara (2010) state that, although pre-primary enrolment has increased substantially in the first decade of the twenty-first century in the Asia Pacific region, huge disparities continue to exist among and within countries. Countries in the region are far from providing equal opportunities for all children from birth. One of the problems that governments face is the competing demand for funding from other important areas such as pollution, disease and infrastructure development [Bray (1998)]. This is why, in some countries such as Cambodia, non-governmental funding is the norm for preschool education [Rao and Pearson (2009)].

Children with special needs are a particular case for concern. Such children have educational needs similar to other children, but these are not always readily provided for. In the context of Brunei, Mundia (2009) noted with concern that there was a lack of contact and coordination between special education in schools and school counselling professionals. Even worse, there are no special education teachers or school counsellors at preschool level in Brunei.

Finally, in regard to the issue of inclusion, Pereira (2016) makes an important point; he argues that while at one level, issues faced by Southeast Asian countries (with his exemplars being Malaysia, Indonesia and Vietnam) are common, solutions have to be tailored to the individual country in line with their differing contextual challenges: the place of religion within education in Indonesia; the tensions between the Malays and other ethnic groups in Malaysia; and issues around minority ethnic groups in Vietnam. He also notes that in Vietnam, three quarters of children attend preschool in urban areas but only about half of them do that in rural areas. Against that baseline, Thailand's Songkhla Province is doing quite well, but the development of services for the excluded should remain a matter for future attention.

\section{Methodology}

This study sought to fulfil a perceived need to determine participating parents' views of the activities of preschool childcare centres which their children attend. It forms part of an existing research and development project, "Preschool Centres Development in Songkhla: A Case Study of Local Curriculum and Integrated Lesson Plans for Early Childhood Development in the Pilot Preschool Centres" (Sornprasith et al., 2015). Instead of undertaking this research and development project separately, it was integrated into a wider work of the Arts and Cultural Centre (ACC), Prince of Songkhla University, based on the value and process of the Thai living culture as the main driving force to develop human potential, which is the main social capital for the sustainability of cultural evolution and inheritance. The second author, a project leader and director of ACC until 2014, has been working with these preschool teachers in the studied area since 2000. Results of this study were also used to enhance the service quality of each childcare centre for developing human potential in early childhood, which will help deliver equity and efficiency (Heckman, 2011).

As noted already, the overarching objective was to study parental expectations of and satisfaction with overall services of preschool centres and to determine factors which affect parents' satisfaction with the preschool education provided in a part of one of Thailand's southern provinces. To address this overall objective, we analysed five separate questions which consider parts of the overall picture. Those questions were as follows:

Q1. What are the expectations of parents regarding teachers' duties in childcare centres?
Services of preschool centres

253 
JME

12,3

Q2. What is the overall level of parental satisfaction with childcare services and the qualifications of staff, including the building and environment of the centre?

Q3. With which dimension(s) of $Q 2$ are parents most and least satisfied?

Q4. What is the level of parental satisfaction with their children's development?

Q5. How are parents' expectations and satisfaction related for each dimension?

We now consider the nature of the data collection process and the type of analysis deployed to examine that data.

\section{The data collection instrument}

In this study, a questionnaire was designed to ask parents about their expectations of teachers' duties and their levels of satisfaction about teachers' knowledge and ability, services, activities and quality of the childcare centre. Satisfaction regarding each aspect was scored on a five-point Likert scale, ranging from least satisfactory, 1, to highly satisfactory, 5 (Likert, 1967).

Although violent incidents have caused concern among people in the three southern border provinces of Thailand and in some districts in Songkhla, which were not part of study area, some sensitive questions such as socio-economic characteristics of respondents were excluded to avoid issues of perceived discrimination during the collection period. However, some information about respondents which concerns a childcare centre was addressed in the questionnaire.

Because this study was a part of the long-term development of a wider project, as noted in the Introduction, the questionnaire was developed mainly by the second author and discussed with the preschool teachers for confirmation of construct and content validity. There was a pilot test of the instrument for concurrent validity and reliability. As a result, some terms of the questionnaire were amended prior to data collection to ensure that parents could understand and give their opinions directly.

\section{The population, data collection and sample}

The population consisted of families in a rural area of Songkhla Province, who had at least one child enrolled in a childcare centre in the educational year from May 2013 to March 2014. The childcare centres were public and organised by local public administration in each Tambon or sub-district, which are the targets of study in the project. Their locations are shown in the map of the area in Figure 1.

Data were gathered from 27 February to 27 April 2014 by a self-administered questionnaire. Parents were asked to complete the questionnaires, which were distributed and collected by a teacher or teaching assistant in each childcare centre. Using a convenience sampling method, the details of the population and the sample are listed in Table I.

As these data were gathered by staff in each childcare centre, the response rate for each childcare centre was probably affected by the number of staff. The collection period started at the end of the second semester, which is another factor that affected the response rate. Therefore, some childcare centres which still had more activities at the end of semester had higher response rates than others.

\section{Data analysis}

Statistical methods that were used included basic descriptive statistics such as means and some fairly straightforward hypothesis testing as described below. Data were analysed using SPSS software. As this study was a part of the wider project for 


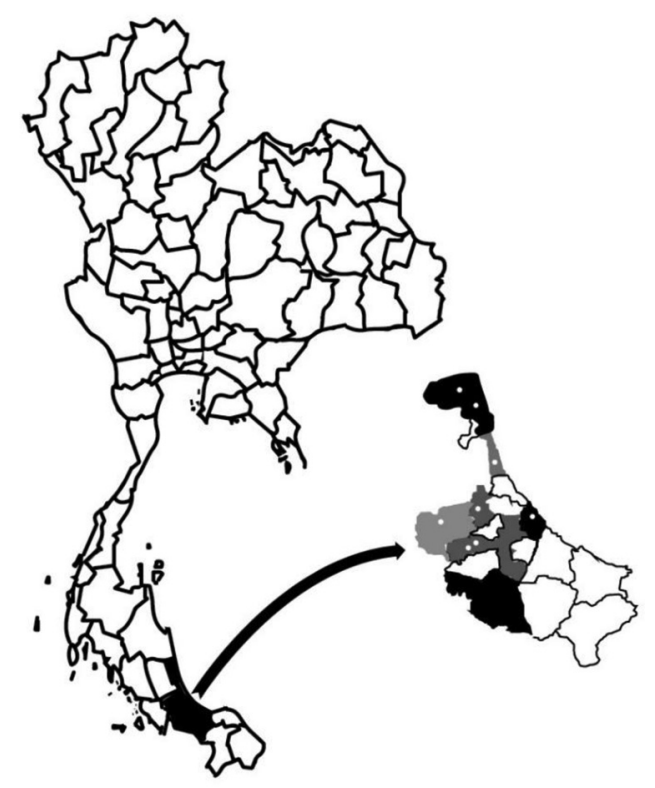

Source: Adapted from Google Maps (2015)

\section{Services of preschool centres}

Figure 1. Map of Songkla and location of the childcare centres in Songkla province, Thailand
Description

Total number of childcare centres in this study

Population size (total no. of enrolled children)

Total number of teaching assistants

Total number of teachers

Total number of staff

Average staff per childcare centre

Average number of children per staff member

Number of responses to questionnaire received

Response rate

Maximum response rate for a childcare centre

Minimum response rate for a childcare centre
Amount

29

1,824

62

53

115
Table I.

Details of population and sample

evaluation of childcare services provided by centres, after using the "Local Curriculum and Integrated Lesson Plans for Early Childhood Development”, Pearson's chi square and significance level (two-tailed test) at 0.01 were used to test the hypothesis of correlation between parents' satisfaction levels and their expectation for teachers' duty in childcare centre. Factors or independent variables in this study were parents' expectations for teachers' duties in childcare centres.

The hypotheses tests were set up along these lines:

Null Hypothesis - HO : Factors or independent variables were not associated with parents' satisfaction levels (dependent variable). 
Alternate hypothesis - H1: Factors or independent variables were associated with parents' satisfaction levels.

If the asymmetric significance (two-sided) or the observed significance level is less than 0.01, it leads us to reject $H O$ and accept $H 1$.

\section{Findings from the analysis}

Information about the respondents

Most respondents had one child enrolled at a childcare centre (81.6 per cent). Most children were either about two-three years old (37.7 per cent) or about three-four years old (38 per cent). Most people who answered the relevant question lived less than $1 \mathrm{~km}$ from a childcare centre ( 41.8 per cent); 17.2 per cent of the values were missing. Most respondents were parents of children ( 85 per cent). Therefore, most children lived with their parents (84.3 per cent) and were picked up by them (73.3 per cent) (Table II).

\section{Respondents' expectations of teachers' duties in their childcare centre}

Respondents could choose their expectations of teachers' duties to include more than one function. The top three teachers' duties were taking care of children, allowing them to have their own development and potential (Exp1 $=85$ per cent); teaching children reading and writing skills and mathematics literacy $(\operatorname{Exp} 2=71$ per cent); and regularly developing teaching methods for children (Exp3 $=70$ per cent). Picking up children from home to take them to a childcare centre was a teacher's duty for which respondents had the lowest expectation. However, almost 50 per cent of respondents expected the teacher to fulfil the role of nannying (performing the functions of a nanny) for their children, including feeding and bathing them and looking after their security (Exp5 $=49$ per cent) (Table III).

\section{Average level of respondents' satisfaction with a childcare service}

Respondents could rate their levels of satisfaction ranging from least satisfactory, 1 , to highly satisfactory, 5, for each dimension of satisfaction such as teachers' knowledge and ability, services, activities and quality of childcare centre. The average levels of respondents' satisfaction fell within quite a narrow range (3.40-4.08).

The dimensions of satisfaction with the highest average rating were as follows:

- knowledge and ability of teachers at a childcare centre (Satis2 $=4.08$ );

- knowledge and ability of the head of a childcare centre (Satis1 = 3.93);

- looking after children's security (Satis10 $=3.91$ );

- teaching and study media and tools (Satis12 = 3.91); and

- children's development (Satis13 $=3.91$ ).

While the dimensions of satisfaction with the lowest average rating were as follows:

- knowledge and ability of teaching assistants at a childcare centre (Satis3 $=3.40$ );

- $\quad$ picking up children (Satis14 $=3.40$ ); and

- environment outside childcare centre (Satis4 = 3.51).

However, the respondents' average overall rating of childcare centres was (Satis19 $=3.79$ ), which sets it at the 42nd percentile of the set (Table IV). 
No.

1. Number with children who were enrolled at one and the same childcare centre

One child

Two children

More than two children

Missing value

Total

2. Ages of children

Two years old

Two-three years old

Three-four years old

More than four years old

Missing value

Total

3. Distance from childcare centre to children's homes

Less than $1 \mathrm{~km}$

$1-2.5 \mathrm{~km}$

$2.5-5 \mathrm{~km}$

$>5 \mathrm{~km}$

Missing value

Total

4. Respondents' relationship with children

Parent

Grandparent

Uncle or aunt

Others

Missing value

Total

5. Children live with

Parent

Grandparent

Uncle or aunt

Others

Missing value

Total

6. Children are picked up by

Parent

Grandparent

Uncle or aunt

Others

Missing value

Total
1,063

139

23

77

1,302

24

491

495

201

91

1,302

544

234

237

63

224

1,302

1,107

128

45

14

1,302

1,098

152

21

15

16

1,302

983

175

76

44

24

1,302
(\%)

Services of preschool

centres

81.6

10.7

1.8

5.9

100.0

257

1.8

37.7

38.0

15.4

7.0

100.0

41.8

18.0

18.2

4.8

17.2

100.0

85.0

9.8

3.5

1.1

0.6

100.0

84.3

11.7

1.6

1.2

1.2

100.0

75.5

13.4

5.8

3.4

1.8

100.0
Table II.

Information about the respondents

Levels of respondents' satisfaction regarding their children's development

Respondents could choose their satisfaction with their child's development in more than one dimension. The top two child development factors were ability to live with others and selfcare (80 per cent), while love for culture/Thai identity and reasoning were the factors with the lowest satisfaction ratings (25 per cent) (Table V). 


\section{Correlation of parents' satisfaction levels and expectations of teachers' duties in childcare} centres

As respondents could express their expectations of teachers' duties in relation to more than one function, data related to each function may be correlated. To analyse the correlation of respondents' expectations of teachers' duties in a childcare centre for each function, Pearson's chi square and significance level (two-tailed test) at 0.01 were used before conducting further analysis. The results in Table VI show that most functions of a teacher's duties are correlated, as reflected by their significance levels (two-tailed tests, at the 0.01 level), except taking care of children to have their own development and potential (Exp1) and nannying children by feeding, bathing and looking after their security (Exp5). The observed significance levels that were less than 0.01 led us to reject $H O$ that states that most functions of a teacher's duties that respondents expected were independent and to accept that most of them were dependent except Exp1 and Exp5. It meant that a group of respondents who had an expectation of the teacher's duty of Exp1 was a different and

Teachers' duty

1. Taking care of children to have their own development and potential (Exp1)

2. Teaching children reading and writing skills and mathematics literacy (Exp2) 71

Table III.

Respondents'

3. Regularly developing teaching methods for children (Exp3)

4. Arranging children activities to stretch the very able kids (Exp4)

5. Nannying children by feeding them, bathing them and looking after their security (Exp5) 49

6. Communicating with parents (Exp6)

7. Producing teaching and studying media and tools (Exp7)

Table IV.

Average level of parents' satisfaction with childcare
Satisfaction

Average

1. Knowledge and ability of the head of a childcare centre (Satis1)

2. Knowledge and ability of teachers of a childcare centre (Satis2)

3. Knowledge and ability of teaching assistants of a childcare centre (Satis3)

4. Environment outside a childcare centre (Satis4)

5. Environment inside a childcare centre (Satis5)

6. Cleanliness of a childcare centre (Satis6)

7. Neatness and tidiness of a childcare centre (Satis7)

8. Quality of lunch meal for children (Satis8)

9. Quality of break time meal for children (Satis9)

10. Looking after children's security (Satis10)

12. Teaching and study media and tools (Satis12)

13. Children's development (Satis13)

14. Picking up Children (Satis14)

16. Parent and teacher meetings at a childcare centre (Satis16)

18. Supporting and development of a childcare centre by local public administrator (Satis18) 
Child development

$(\%)$

1. Live with others

2. Self-care

3. Emotion and mind

4. Body

5. Language/communication

6. Manner and etiquette

7. Creativity

8. Art/music

9. Moral and ethics

10. Decision-making

11. Knowing for community

12. Love for nature/environment

13. Love for culture/Thai Identity

14. Reasoning
Services of preschool centres

259

Table V.

Parents' satisfaction with their child's development, on a range of elements, in decreasing rank

separate one from the group of respondents who had an expectation of the teacher's duty in respect of Exp5. Therefore, Exp1 and Exp5 are functions to represent respondents' expectations of teachers' duty for further analysis. Furthermore, this different expectation of respondents or parents also implied a conflicting perspective of teachers' roles in the infant/ toddler classroom (Wilgus, 2005).

In Table VII, we examine correlations between the selected customer expectation factors and customer satisfaction factors. This highlights whether the parents' expectations (or hopes) were in fact realised in practice in the sample centres. We focus on factors of Satis (i), where $\mathrm{i}=1,2,3$ and 15 , because they refer specifically to respondents'/parents' perceptions of the effectiveness of the teaching staff in the centres ( $i=1,2$ and 3 ) and the interaction between the two types of adults $(i=15)$.

Examination of these data showed that the correlations of these selected expectations in relation to only three dimensions of satisfaction were significant at the 0.01 level, namely, in conjunction with Exp 1 (the expectation that teaching staff would facilitate children's individual development):

- knowledge and ability of the head of childcare centre (Satis1) and in relation to Exp 5 (effective child nanny);

- knowledge and ability of teacher assistant of childcare centre (Satis3); and

- participating in activities at a childcare centre (Satis15).

The relationship between Exp 5 and knowledge and ability of teachers of the childcare centre (Satis2) was significant at the lower level of 0.05 . This led us to reject $H O$, which argues that the variables were not associated and to accept the alternate hypothesis, i.e. accept that the variables were associated. This means the following:

- The respondents who expected teacher's duty of taking care of children so as to allow them to have their own development and potential (Exp1) got more satisfaction with knowledge and ability of the head of childcare centre (Satis1).

- The respondents who expected teacher's duty on nannying children by feeding them, bathing them and looking after their security (Exp5) got more satisfaction with knowledge and ability of teacher of childcare centre (Satis2), knowledge and ability of teacher assistant of childcare centre (Satis3) and participating in activities at childcare centres (Satis15). 
JME

12,3

260
Table VI.

Correlation among functions of a teacher's duties

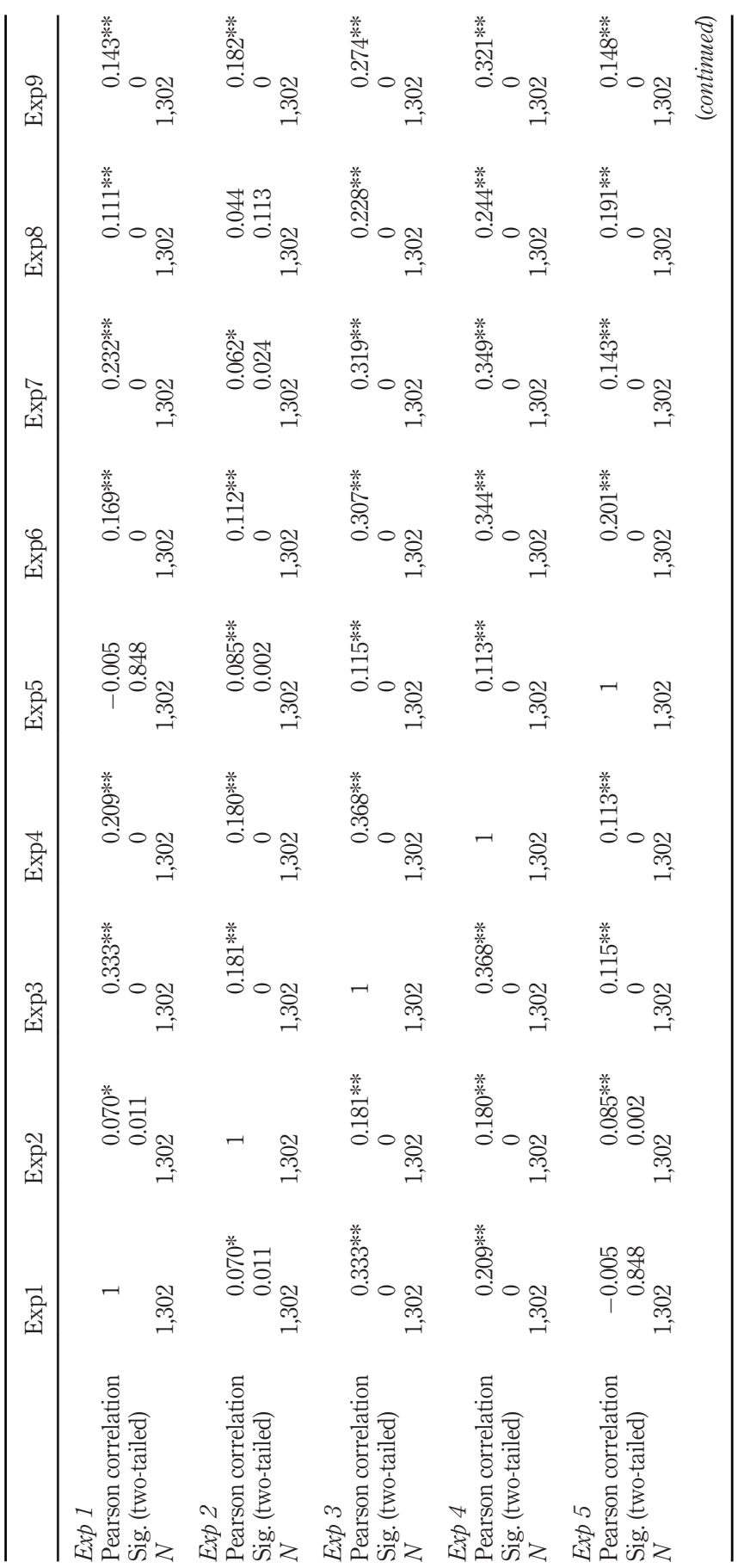

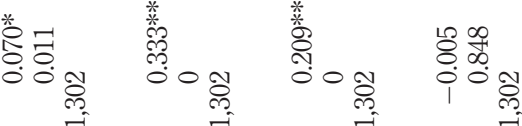




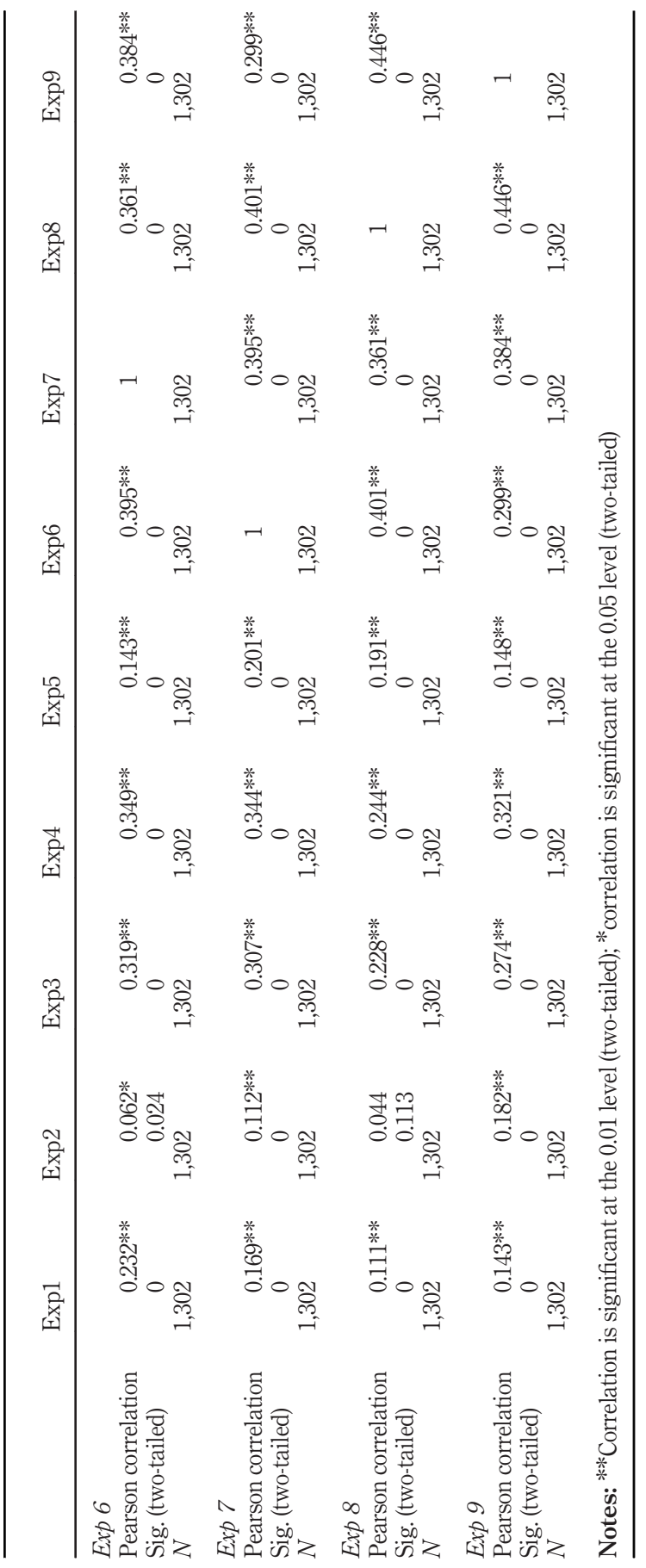

Services of preschool centres 


\section{JME \\ 12,3}

\begin{tabular}{lcccrrr}
\hline & Exp1 & Exp5 & Satis1 & Satis2 & Satis3 & Satis15 \\
\hline Exp 1 & \multicolumn{7}{c}{} & & & \\
Pearson correlation & 1 & -0.005 & $0.150 * *$ & 0.036 & -0.053 & 0.001 \\
Sig. (two-tailed) & & 0.848 & 0.000 & 0.197 & 0.057 & 0.979 \\
$N$ & 1,302 & 1,302 & 1,302 & 1,302 & 1,302 & 1,302
\end{tabular}

262

\section{Exp 5}

Pearson correlation

Sig. (two-tailed)

N
$-0.005$
-0.005
0.848
1,302

1

$-0.023$

0.410

1,302

1,302

$0.068^{*}$
0.014
1,302

$0.080^{* *}$
0.004
1,302
$0.077 * *$
0.006

Satis 1

Pearson correlation

Sig. (two-tailed)

N

$\begin{array}{cc}0.150^{* *} & -0.023 \\ 0.000 & 0.410 \\ 1,302 & 1,302\end{array}$

1

1,302

$\begin{aligned} & 0.403^{* * *} \\ & 0.000 \\ & 1,302\end{aligned}$

$0.127^{* *}$
0.000
1,302

$0.320^{* * *}$

0.000

Satis 2

Pearson correlation

Sig. (two-tailed)

N

0.036
0.197
1,302
$0.068^{*}$
0.014
1,302

Satis 3

Pearson correlation

Sig. (two-tailed)

N
$-0.053$
0.057
1,302

$0.403^{* *}$
0.000
1,302

1
1,302

\begin{tabular}{ll}
$0.293^{* *}$ & \multicolumn{1}{c}{$0.370 * *$} \\
0.000 & 0.000 \\
1,302 & 1,302
\end{tabular}

\section{Satis 15}

Table VII.

Correlations between selected expectation and satisfaction factors

Pearson correlation

0.001
0.979
1,302

$\begin{array}{ll}0.080^{* *} & \\ 0.004 & 0.127^{* *} \\ 1,302 & 1,302\end{array}$
$0.293 * *$
0.000 1,302
1
1,302
$0.229 * *$ 0.000
1,302

Sig. (two-tailed)

$N$
$0.077^{* * *}$ 1,302
0.320 **
0.000
1,302

0.370 **
0.000
1,302
$0.229^{* *}$
0.000

Notes: ${ }^{* *}$ Correlation is significant at the 0.01 level (two-tailed); ${ }^{*}$ correlation is significant at the 0.05 level (two-tailed)

The last Table (VII) also shows a strong intra-correlation within this subset of parent satisfaction elements.

\section{Conclusion}

Overall, given the location and non-compulsory nature of the childcare provision being assessed, it would seem fair to say that the answer to the overarching objective was fairly positive. Expectations were non-trivial; parents looked for more than "baby-minding" and expected there to be some appropriately qualified staff. The perceived satisfaction levels indicate that there is scope for improvement, but the picture is not unduly negative. In short, parents and guardians of the children attending the Songkhla facilities believed that their charges are being properly cared for by acceptable staff, are being helped to develop socially and are learning some important basic intellectual material (such as numeracy and reading). However, it should be noted that the official aims of the "Local Curriculum and Integrated Lesson Plans for Early Childhood Development" programme did not specifically focus on the acquisition of mathematical knowledge. Hence, we only report that parents perceived some knowledge acquisition in this field positively relative to their own expectations, distinct from the programme's specified objectives.

In more detail, the results of the study showed that the majority of respondents were parents and had one child enrolled at a childcare centre. Most children were three-four years 
old and lived less than $1 \mathrm{~km}$ from each childcare centre. Although respondents were allowed to choose their expectation for more than two functions, the top three teachers' duties of respondents' expectation were taking care of children, allowing them to have their own development and potential; teaching children reading and writing skills and mathematics literacy; and regularly developing teaching methods for children. The study showed moderate to high level of respondents' satisfaction with teachers' knowledge and ability, services, activities and quality of childcare centre. Although expectations such as teaching assistants' knowledge and ability and picking up children had the lowest average rating, they had high satisfaction of their child's development, which were live with others and selfcare. The respondents' expectations about taking care of children to allow them to achieve their own development and potential affected the levels of satisfaction in respect of head teachers' knowledge and ability. The respondent's expectation on nannying children by feeding them, bathing them and looking after their security affected the levels of satisfaction in respects of both teacher and assistant teachers' knowledge and ability and participating in activities at a childcare centre.

Expectations of respondents about taking care of children such that they have their own development path and potential were not highly correlated with perceptions of satisfaction in respect to the nannying of children, by feeding, bathing and looking after their security. This suggested some element of conflict of perspectives around the teacher's role in the infant/toddler classroom. It inevitably denies that such perspectives relate to the relationship between parent and teacher. Many research works have clearly shown that parent-teacher relationships lead to increased parental involvement, which has been shown to have a significant and lasting impact on children's academic achievement (for more details, see Knopf and Swick, 2007). One result was to show that different expectations affected levels of satisfaction in respects to different dimensions. Parents who expected a teacher's duty to focus on child development were more likely to be more satisfied with the knowledge and ability of a head teacher of a childcare centre, whereas parents who expected a teacher's duty to focus on factors such as feeding tended to have more satisfaction with the knowledge and ability of teachers and assistant teachers and participating in activities at a childcare centre. These results implied that the teaching direction (or focus) of a head teacher may concentrate on child development issues, while teachers and teaching assistants may concentrate more on the nanny role. Although both these aspects of a teacher's duties fall within their job description and responsibility to provide a good service in a childcare centre, other components such as parental involvement are needed to bring about good-quality or effective education with full potential for children's development in all ways. Therefore, to build a parent-school partnership into the life of a childcare centre with space for providing parent feedback and involvement, as well as exchanging views of their expectations between parents and all staff, is what is truly required to deliver a vision of their (mutually understood) ideal childcare centre.

\section{Implications and utility of the study findings}

As noted, this study began with the need for parents' views in evaluating the childcare service of centres in a Thai province, which forms part of a sponsored research and development project, "Preschool Centres Development in Songkhla: A Case Study of Local Curriculum and Integrated Lesson Plans for Early Childhood Development in the Pilot Preschool Centres" (Sornprasit et al., 2015). After conducting data analysis, a workshop for discussion of these results with head teachers or representatives of childcare centres and local public administration was held. This two-way communication brought about a useful and direct implication because teachers and representatives of a childcare centre were 
allowed to ask questions and make comments to help them understand it and to use the results of this study in each centre to improve their service. The results of this project were not a direct output of a unified local curriculum, with associated integrated lesson plans such as those observed in the project and used in the childcare centres, because they use various curricula, including a National Curriculum and various teaching methods advised by other institutions and the local public administration. Nevertheless, the researchers can use these results and their feedback as a valuable part of the larger project.

One interesting outcome, as noted before, was the dissonance between perceptions of importance of what may be seen as early-stage academic development of and the care-giving and social nurture of the children attending the kind of Thai preschool centres studied. This suggests that it would likely be beneficial for an enhanced explanation to the parents of existing and potential students of the benefits of a holistic approach to the development of their children. Social, health and academic development are all important for the child, and all of them should be moulded into an attractive, unified experience. Finally, lessons learnt in the southern province of Songkhla are likely to be equally applicable across the rest of Thailand, even in Bangkok, albeit the "metropolitan elite" may feel themselves to be special. It may also be reasonable to speculate that many findings may also apply to other countries in the region. After all, why should good-quality preschool provision be fundamentally different in Malaysia, Vietnam, Brunei or wherever? To take a very particular case in point, Southern Thailand and the northern states of Malaysia have much in common. Indeed, the border between the two countries, as they now are, was adjusted as recently as 1909 under a treaty between Siam (Thailand) and Britain.

The reported study's usefulness or utility could be further enhanced if some of the factors related to the inclusion/exclusion issue were to be addressed in a future phase of work. The most basic issue would probably be to explore why those children not participating in preschool provision in Songkhla are absent. If possible, it would be helpful to also compare that position with that of other provinces in Thailand. Pereira's (2016) comment that solutions must be crafted to best fit contexts perhaps raises the issue of the Buddhist/Muslim mix in Songkhla (as the province is located in the South of Thailand, there are many more Muslims there than in the rest of the country). Pereira with reference to Indonesia and Young et al. (2017) in the Brunei context make explicit reference to the potential tensions between modern, educational thinking and the perceived needs of Islam in school, and presumably also preschool, education.

Finally, one would speculate that, sadly, the opportunities and needs of disabled children, be they physical or mental disabilities, are likely to be rather low down the priorities list of many funders and providers, in a setting of intrinsic shortage. Any evidence to the contrary would be both interesting and a source of hope.

\section{References}

Aboud, F.E. (2006), "Evaluation of an early childhood preschool program in rural Bangladesh", Early Childhood Research Quarterly, Vol. 21 No. 1, pp. 46-60.

Bray, M. (1998), "Financing education in developing Asia: themes, tensions, and policies", International Journal of Educational Research, Vol. 29 No. 7, pp. 627-642.

Dalli, C., White, E.J., Rockel, J. and Duhn, I. (2011), "Quality early childhood education for under-twoyear-olds: what should it look like?", Report for Ministry of Education, ISBN: 978-0-47836750-8 (web).

de Los Angeles-Bantista, F. (2004), Early Childhood Care and Education in South-East Asia: Working for Access, Quality and Inclusion in Thailand, the Philippines and Viet Nam, UNESCO, Bangkok. 
Department of Local Administration Organization (DLAO) (2014), "Summary of childcare centres from the whole kingdom", Resource Document, DLAO, available at: www.dla.go.th/upload/document/ type2/2014/8/14032_2_1408606388468.xls?time=1415982409950 (accessed 25 June 2014).

Drugli, M.B. and Undheim, A.M. (2012), "Partnership between parents and caregivers of young children in full-time day-care", Child Care in Practice, Vol. 18 No. 1, pp. 51-65.

Dunn, L. and Dasananda, S. (1995), "Parental resistance to developmentally appropriate practice in Thailand", Educational Research Information Centre, US Department of Education (ED 390 527).

Frey, A.J., Small, J., Feil, E., Seeley, J., Walker, H. and Golly, A. (2013), "The feasibility of first step to success with pre-schoolers", Children \& Schools, Vol. 35 No. 3, pp. 171-186.

Gangopadhyay, P. and Bhattacharyay, B.N. (2015), "On the economics of social inclusion and protection in ASEAN economies, India and the People's Republic of China", CESifo Area Conference on Employment and Social Protection, 15-16 May, Munich.

Google Maps (2015), “Thailand, country map”, Resource Document Google, available at: www.google. co.th/maps/place/ (accessed 25 July 2015).

Heckman, J.J. (2011), "The economics of inequality: the value of early childhood education”, Education Digest: Essential Readings Condensed for Quick Review, Vol. 77 No. 4, pp. 4-11.

Ho, C.W.D. (2008), "Exploring the definition of quality early childhood programmes in a market driven context: case studies of two Hong Kong pre-schools", International Journal of Early Years Education, Vol. 16 No. 3, pp. 223-236.

Israsena, V. (2007), "Thai teachers' beliefs about learner centred education: implications for success for life Thailand", Doctor of Education Thesis, University of North Texas, Texas.

Kabitcibasi, C., Sunar, D. and Bekman, S. (2001), "Long-term effects of early intervention: Turkish lowincome mothers and children”, Applied Developmental Psychology, Vol. 22 No. 4, pp. 333-361.

Kellingham, T.L., Aksoy, L., Andreassen, T.W. and Estrin, D. (2006), "Does parent satisfaction with a childcare provider matter for loyalty", Journal of Consumer Marketing, Vol. 23 No. 7, pp. 470-479.

Kim, G.J. and Umayahara, M. (2010), "Early childhood care and education: building the foundation for lifelong learning and the future of the nations of Asia and the Pacific", International Journal of Child Care and Education Policy, Vol. 4 No. 2, pp. 1-13.

Knopf, H.T. and Swick, K.J. (2007), "How parents feel about their child's teacher/school: implications for early childhood professionals", Early Childhood Education Journal, Vol. 34 No. 4, pp. 291-296.

Likert, R. (1967), The Human Organisation: Its Management and Value, McGraw Hill, New York.

Liu, W.P., Yeung, A.S. and Farmer, S. (2001), "What do parents want from day-care services? Perspective from Australia”, Early Childhood Research Quarterly, Vol. 16 No. 3, pp. 385-393.

Marasi, P. and Sewdon, C. (2013), "Factors affecting the efficiency of childcare centres under local administration development", Paper presented at the Mahasarakam Research No. 10, Mahasarakam University.

Ministry of Education (MOE) (2013), "National curriculum for preschool education B.E. 2546 (2013)", Kurusapa, Bangkok.

Mundia, L. (2009), "Implementation of inclusive education in Brunei Darussalam: review of possible implications for school counselors", Electronic Journal of Inclusive Education, Vol. 2 No. 4, p. 30, available at: http://corescholar.libraries.wright.edu/ejie/vol2/issue4/5

Office of the National Education Commission (ONEC) (1999), "National Education Act B.E. 2542 (1999)", Prig wan Communication, Ltd., Bangkok.

Office of the National Education Commission (ONEC) (2007), "Strategic plan and policy for preschool education (0-5 years old) in 2007-2016", Prig wan Communication, Ltd., Bangkok.

Omar, N.A., Nazri, M.A., Abu, N.K. and Omar, Z. (2009), "Parents' perceived service quality, satisfaction and trust of a childcare centre", International Review of Business Research Papers, Vol. 5 No. 5, pp. 299-314. 
Pereira, J.D. (2016), "Equity, access and educational quality in three South-East Asian countries - the case of Indonesia, Malaysia and Viet Nam”, Literature Review, The Head Foundation, July 2016.

Powell, D.R., Son, S.-H., File, N.M. and San Juan, R.R. (2010), "Parent-school relationships and children's academic and social outcomes in public school pre-kindergarten”, Journal of Social Psychology, Vol. 48 No. 4, pp. 269-292.

Rao, N. and Pearson, V. (2009), "Early childhood care and education in Cambodia", International Journal of Child Care and Education Policy, Vol. 3 No. 1, pp. 13-26.

Sornprasith, A., Prayukvong, W., Subaramdecha, R., Tongkong, A. and Laohaviriyakamol, S. (2015), PreSchool Centres Development in Songkhla: A Case Study of Local Curriculum and Integrated Lesson Plans for Early Childhood Development in Pilot Pre-School Centres, Prince of Songkhla University, Songkhla.

Tongsow, S. and Runegsuwan, C. (2013), "Development of pre-school teachers to prepare plans of learning activities", Paper presented at the Graduate Conference No. 14, on 22 February 2013, Khonkaen University.

Wilgus, G. (2005), "If you carry him around all the time at home, he expects one of us to carry him around all day here and there are only TWO of us! Parents', teachers' and administrators' beliefs about the parents' role in the infant/toddler centre", Journal of Early Childhood Teacher Education, Vol. 26 No. 3, pp. 259-273.

Young, A., Muhammad, N.H.J., Bakar, O., O'Leary, P. and Abdalla, M. (2017), "Children in Brunei Darussalam: their education, legal and social protections", International Journal of Islamic Thought, Vol. 11 No. 1, pp. 6-16.

\section{About the authors}

Wanna Prayukvong is an Associate Professor at Mahidol University's Nakhon Sawan campus in northern Thailand. She originally trained and practised as a civil engineer before taking a master's degree in Economics and teaching and researching in several Thai universities. She completed $\mathrm{PhD}$ in Buddhist Economics and its application in Thai businesses. Her areas of interest for research are Buddhist economics and sustainable development. She has published a number of papers in both Thai and international journals.

Amporn Sornprasith is an Assistant Professor and the Founder of the Arts and Cultural Centre at the Prince of Songkhla University, Songkhla Province, South Thailand. Amporn has been the Director of the Arts and Cultural Centre for 24 years (1989-2013). She has a bachelor's degree in Chemistry and a master's degree in Pharmacology. As Director of the Arts and Cultural Centre, she has worked and researched for community empowerment and has developed an interest in the area of human potential development and preschool education since 1999. Her current research interests concern early childhood education provision in Thailand.

Morris John Foster is an Emeritus Fellow of the Faculty of Business and Law at Kingston University, in London; before that he was Associate Dean for a decade at the same university and found the Faculty's Asia Business Research Centre. His current research interests are the effectiveness of strategic planning; evaluation processes for foreign direct investment; and business in China and South East Asia. He has published in a wide range of journals of international standing. He has been a Visiting Professor at universities in China, Thailand and Malaysia; he has undertaken consulting assignments for major firms in the private sector, the UK's Audit Commission and educational establishments in the UK and overseas. Morris John Foster is the corresponding author and can be contacted at: foster@kingston.ac.uk

For instructions on how to order reprints of this article, please visit our website:

www.emeraldgrouppublishing.com/licensing/reprints.htm

Or contact us for further details: permissions@emeraldinsight.com 